This is the peer reviewed version of the following article: Fernández-Jaén A, Suela J, Fernández-Mayoralas DM, Fernández-Perrone AL, Wotton KR, Dietrich S, Castellanos MC, Cigudosa JC, Calleja-Pérez B, LópezMartín S. 2014. Microduplication 10q24.31 in a Spanish girl with scoliosis and myopathy: The critical role of LBX. Am J Med Genet Part A 164A:2074-2078., which has been published in final form at http://onlinelibrary. wiley.com/doi/10.1002/ajmg.a.36589/full This article may be used for non-commercial purposes in accordance with Wiley Terms and Conditions for Self-Archiving.

\title{
Microduplication 10q24.31 in a Spanish girl with scoliosis and myopathy: The critical role of $L B X$
}

\author{
Alberto Fernández-Jaén, Javier Suela, Daniel Martín Fernández-Mayoralas, Ana Laura Fernández-Perrone, Karl \\ R. Wotton, Susanne Dietrich, Maria del Carmen Castellanos, Juan C. Cigudosa, Beatriz Calleja-Pérez, Sara \\ López-Martín
}

\begin{abstract}
LBX1 plays a cardinal role in neuronal and muscular development in animal models. Its function in humans is unknown; it has been reported as a candidate gene for idiopathic scoliosis. Our goal is to document the first clinical case of a microduplication at 10q24.31 (chr10:102927883-103053612, hg19), affecting exclusively $L B X 1$. The patient, a 12-year-old girl, showed attention problems, dyspraxia, idiopathic congenital scoliosis, and marked hypotrophy of paravertebral muscles. Her paternal aunt had a severe and progressive myopathy with a genetic study that revealed the same duplication. We propose to consider genetic studies, particularly of $L B X 1$, in patients with scoliosis and/or hypotrophy-hypoplasia of paravertebral muscles of unknown etiology.
\end{abstract}

\section{Introduction}

$L B X$ genes have essential functions in development, including their role in neural and mesodermal cell specification [Jagla et al., 1998; Garcia-Fernandez, 2005]. LBX1 is a homeodomain-containing transcription factor related to the Drosophila ladybird genes that was first discovered by Jagla et al. [1998]. In vertebrates, $L B X 1$ is expressed in developing skeletal muscles and the nervous system. During initial embryonic mouse development, $L b x 1$ is required for the specification of several populations of dorsal spinal cord interneurons and neural tube closure [Kruger et al., 2002] and it is essential somatosensory fate determination in relay neurons in the hindbrain [Sieber et al., 2007]. During later mouse neurogenesis, $L b x 1$ expression outlines a basal GABAergic/glycinergic differentiation state for dorsal horn neurons [Muller et al., 2002] and the loss of this gene selectively eliminates these inhibitory neurons. 
LBX1 plays an important role in the migration of hypaxial muscle precursor cells [Martin and Harland, 2006]. It regulates properties specific for the migratory lineage of muscle precursors. LBX1 controls the expression of genes necessary for the recognition of cues that guide migrating muscle precursors and maintain their migratory potential [Brohmann et al., 2000]. Watanabe et al. [2007, 2011] identified $L b x 1$ in activated satellite cells of adult mice. They suggested that $L b x 1$ plays an important role in the regeneration of muscle fibers. In addition to its importance in neuronal and muscle development, this homeobox gene is also expressed in a subset of cardioblasts of the cardiac neural crest during heart formation [Schafer et al., 2003; Schmitteckert et al., 2011].

The specific functions of $L B X 1$ in humans are unknown. There are no cases in the scientific literature of patients with isolated mutations, deletions, or duplications of this gene. Recently, a genome-wide association study was performed in a Japanese population and three SNPs (single nucleotide polymorphisms), near LBX1 on 10q24.31, were associated with adolescent idiopathic scoliosis [Takahashi et al., 2011; Gao et al., 2013]. Indeed, $L B X 1$ has been identified as a candidate gene for familial idiopathic scoliosis [Marosy et al., 2010]. Here, we describe the first case of the isolated microduplication of this gene.

\section{Clinical Report}

A 12-year-old Spanish female patient joined our study because of her attention difficulties and poor fine and gross motor abilities. She was born after a multiple gestation. Birth was via elective cesarean without complications in the 38 th week of gestation. Her weight at birth was 2,500 g. She was diagnosed with a congenital scoliosis due to a complex anterior central malformation of the cervical and dorsal vertebrae (see Figs. 1 and 2). She started crawling at 13 months and walking at 17 months. Her speech and language development was normal. She had poor coordination, which her family attributed to her non-progressive congenital scoliosis treated with a medical corset. Her coordination improved with age. She had had attention and inhibitory control problems since her first school years and exhibited very low academic performance. Her parents emphasized her poor working memory and pointed out facial motor tics in the last few years. 


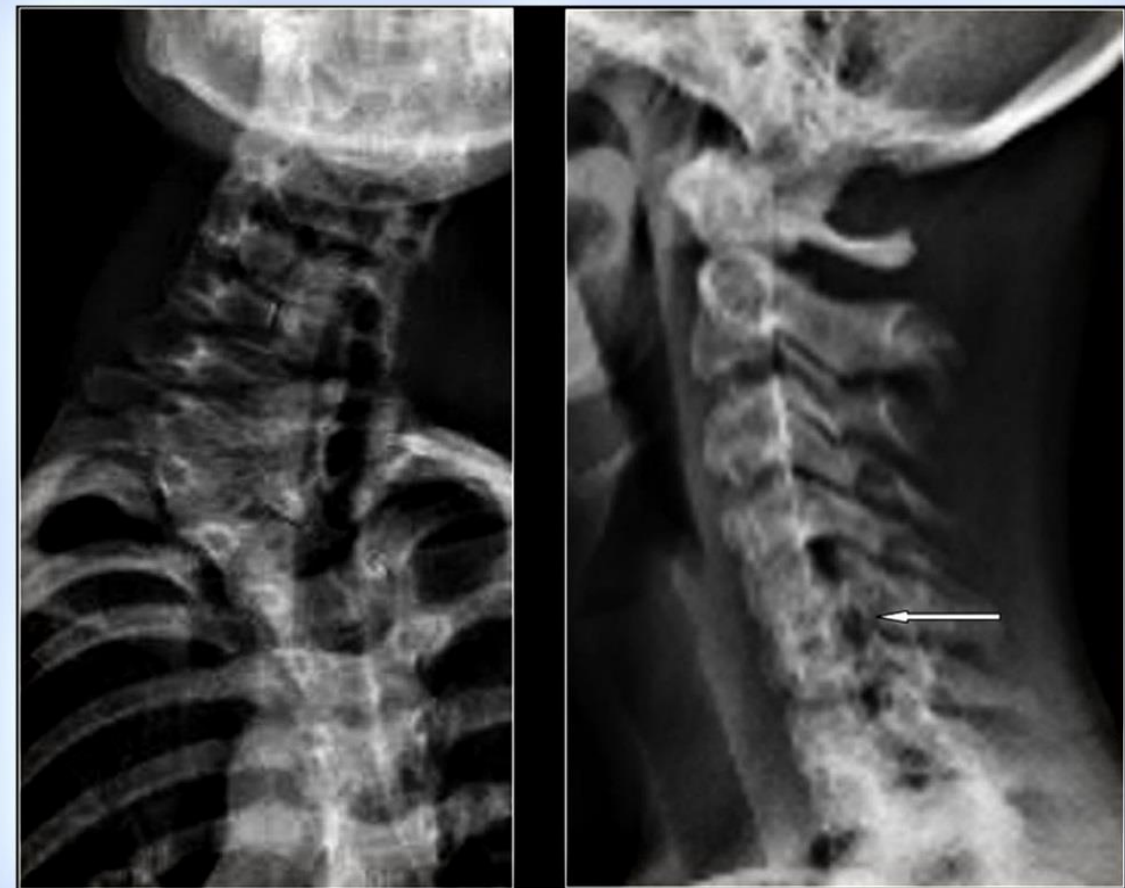

FIG. 1. Posteroanterior and lateral radiographs of cervico-dorsal spine. Severe left cervico-dorsal scoliosis with cervical hypolordosis. Multiple block vertebrae C5-D1 (white arrow).

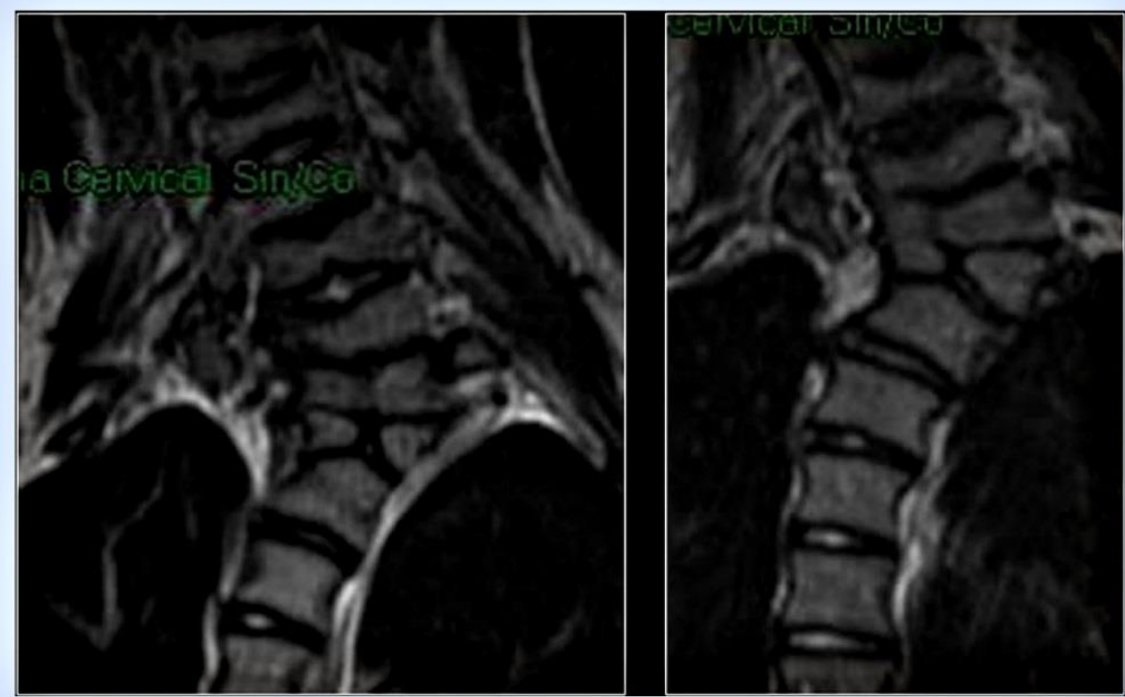

FIG. 2. MRI T2-weighted coronal view of cervico-dorsal spinal column. Partial fusion of $C ?$ and D1 vertebrae. Partial fusion of D1 vertebra and D2 hemivertebra. 
A neurological examination revealed low axial muscular tone, with normal passive and active distal tone. Deep tendon and plantar reflexes were normal. A marked abnormal spinal curvature was observed in the Adam's forward bending test; no associated morphological alterations (pits, masses, etc.) or pigmentary changes were seen in her skin. She had severe hypotrophy of paravertebral muscles and deficient fine and gross motor abilities. A physical examination showed no dysmorphic features. Cardiovascular examination and ECG were normal.

Her parents and her dizygotic twin were healthy, without dysmorphic features, physical malformations, or learning problems. Her paternal aunt had been studied at other centers because of early onset progressive myopathy and a severe physical disability present since young adulthood; she used a wheelchair.

After consultation, a cerebral magnetic resonance image (MRI) was performed on the proposita with normal results. Array comparative genomic hybridization (aCGH) analysis defined a $130 \mathrm{~kb}$ duplication at 10q24.31 (chr10:102927883-103053612, NCBI37-National Center for Biotechnology Information), containing LBX1 (Fig. 3). Identical aCGH analysis was carried out in a blood sample of her paternal aunt and the same result was obtained.

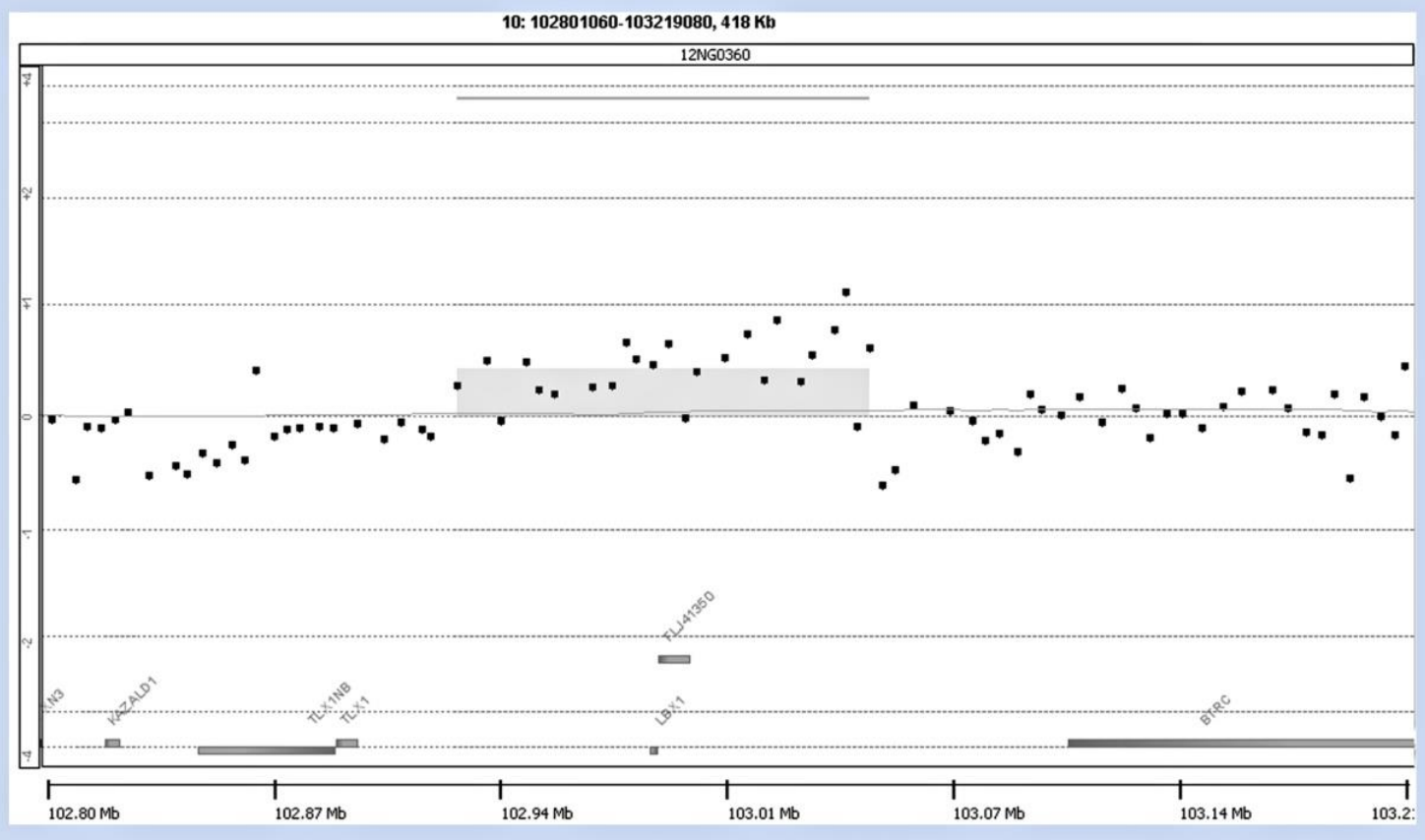

FIG. 3. Array CGH plot of the clinical case, showing a microduplication 10q24.31 (chr10:102927883-103053612), affecting LBX1. Duplicated segment is shaded in gray.

Figure 3. Array CGH plot of the clinical case, showing a microduplication 10q24.31 (chr10:102927883103053612), affecting LBX1. Duplicated segment is shaded in gray. 
After this discovery, a complete blood analysis with biochemical markers of muscular damage, electromyography, genetic studies for the rest of paternal family, and a spine MRI for her father were requested. Two years later, we have no information about the patient's progress; the solicited studies were not carried out.

\section{Materials and Methods}

\section{Genetic Study}

Array CGH was carried out using the whole-genome Agilent SurePrint G3 Human CGH Microarray 2×400K AMADID 021850, manufactured and provided by Agilent Technologies, Santa Clara, CA. Experiments were conducted according to the manufacturer's protocol with slight modifications. In brief, $500 \mathrm{ng}$ of genomic DNA was labeled with Cy5 (patient) or Cy3 (control). After clean up, the labeled fragments were pooled and $5 \mu$ l Cot-1 DNA ( $1 \mathrm{mg} / \mathrm{ml}$ ), blocking agent, and hybridization buffer were added. This mixture was hybridized on the microarrays for $24 \mathrm{hr}$ at $65^{\circ} \mathrm{C}$. After washing, the slides were scanned using an Agilent Microarray Scanner, quantified with Feature Extraction software 9.1, and analyzed with CGH Analytics software, both from Agilent Technologies. The following conventional settings were used: Aberration Algorithm: ADM-2; Threshold: 6.0; Window Size: $0.2 \mathrm{Mb}$; and Filter: five probes, $\mathrm{mx} \log 2$ ratio $=0.29$. These parameters were adjusted when needed.

\section{Discussion}

This is the first patient with a microduplication of 10q24 affecting exclusively LBX1. The report of this family supports the critical role of this gene in muscular development and preservation [Watanabe et al., 2007]. Beyond its role in the myoblast migration, this study demonstrates $L B X 1$ 's function in the development of the paraxial mesoderm.

There are other reports with deletions or duplications in 10q24 [Gurrieri et al., 1996; de Mollerat et al., 2003; Roscioli et al., 2004; Dai et al., 2013] and international databases [Firth et al., 2009]. These cases have more extensive genomic aberrations, affecting several genes. Indeed, the split-hand/foot malformation 3 (SHFM3) is linked to this region [Gurrieri et al., 1996; de Mollerat et al., 2003; Roscioli et al., 2004; Dai et al., 2013]. This disorder may be a contiguous gene duplication syndrome [Lyle et al., 2006] characterized by a limb malformation involving the central rays of the distal limbs and characterized by syndactyly, median clefts of the hands and feet, and aplasia or hypoplasia of the phalanges, metacarpals, and metatarsals. Mutations of FBXW4 are suspected to be responsible for this syndrome [de Mollerat et al., 2003]. However, most patients with SHFM3 have partial or complete duplication of FBXW4, LBX1, and BTRC [Gurrieri et al., 1996]. These microduplications are transmitted from unaffected carriers or affected parents to offspring [Everman et 
al., 2006]. Variable penetrance, underlying parental mosaicism, or the function of regulatory genes could explain the heterogeneity of these genetic alterations. Although $L B X 1$ has been related to idiopathic scoliosis [Marosy et al., 2010; Takahashi et al., 2011; Gao et al., 2013], there are no cases with SHFM3 with described scoliosis, vertebrae malformations, or myopathy. Furthermore, 15\% of SHFM3 patients have intellectual disability, usually severe [Elliott and Evans, 2006]. Intellectual disability, delayed speech, and behavioral problems have been described in patients with 10q24 duplications [Firth et al., 2009].

Deregulated $L B X 1$ expression may interfere with segmentation of the paraxial mesoderm, patterning of the neural tube [Gross et al., 2002; Kruger et al., 2002] or with the satellite cell function, directly or indirectly causing myopathy and/or scoliosis [Dietrich et al., 1998; Mennerich and Braun, 2001; Martin and Harland, 2006; Wotton et al., 2008; Ochi and Westerfield, 2009; Watanabe et al., 2011]. Besides, mutations in the $L B X 1$ coding region may be associated with a human-specific phenotype or act as a dominant negative with the potential to cause more severe phenotypes than those observed in animal models (K. Wotton and $\mathrm{S}$. Dietrich, unpublished observations).

It is hard to relate $L B X 1$ to the attention difficulties of the patient. Attention deficit disorder is a problem with a very high prevalence [Willcutt, 2012] and polygenic etiology [Neale et al., 2010]; the presence of the patient's executive dysfunction could therefore be coincidental. However, the role of $\angle B X 1$ in neuronal development, specifically of the hindbrain [Sieber et al., 2007] and the widely studied function of the cerebellum in attention processes [Martin Fernandez-Mayoralas et al., 2010; Bledsoe et al., 2011; Massat et al., 2012; Vaidya, 2012], could explain this problem. In addition, other cases with duplications of 10q24 showed similar or more severe cognitive problems [Elliott and Evans, 2006; Firth et al., 2009]; nevertheless, these patients had duplications involving several genes.

In conclusion, based on the present case, perhaps one should consider genetic studies, particularly of $L B X 1$, in patients with scoliosis and/or hypotrophy-hypoplasia of paravertebral muscles of unknown etiology. As our case reveals, identification of an $L B X 1$ duplication could explain the clinical features. The detection of a genomic anomaly affecting $L B X 1$ may be decisive for genetic counseling. 


\section{References}

Bledsoe JC, Semrud-Clikeman M, Pliszka SR. 2011. Neuroanatomical and neuropsychological correlates of the cerebellum in children with attention-deficit/hyperactivity disorder-combined type. J Am Acad Child Adolesc Psychiatry 50:593-601.

Brohmann H, Jagla K, Birchmeier C. 2000. The role of Lbx1 in migration of muscle precursor cells. Development127:437-445.

Dai L, Deng Y, Li N, Xie L, Mao M, Zhu J. 2013. Discontinuous microduplications at chromosome 10q24.31 identified in a Chinese family with split hand and foot malformation. BMC Med Genet 14:45.

de Mollerat XJ, Gurrieri F, Morgan CT, Sangiorgi E, Everman DB, Gaspari P, Amiel J, Bamshad MJ, Lyle R, Blouin $\mathrm{JL}$, Allanson JE, Le Marec B, Wilson M, Braverman NE, Radhakrishna U, Delozier-Blanchet C, Abbott A, Elghouzzi V, Antonarakis S, Stevenson RE, Munnich A, Neri G, Schwartz CE. 2003. A genomic rearrangement resulting in a tandem duplication is associated with split hand-split foot malformation 3 (SHFM3) at 10q24. Hum Mol Genet12:1959-1971.

Dietrich S, Schubert FR, Healy C, Sharpe PT, Lumsden A. 1998. Specification of the hypaxial musculature.Development 125:2235-2249.

Elliott AM, Evans JA. 2006. Genotype-phenotype correlations in mapped split hand foot malformation (SHFM) patients. Am J Med Genet A 140:1419-1427.

Everman DB, Morgan CT, Lyle R, Laughridge ME, Bamshad MJ, Clarkson KB, Colby R, Gurrieri F, Innes AM,Roberson J, Schrander-Stumpel C, van Bokhoven H, Antonarakis SE, Schwartz CE. 2006. Frequency of genomic rearrangements involving the SHFM3 locus at chromosome 10q24 in syndromic and non-syndromic split-hand/foot malformation. Am J Med Genet A 140:1375-1383.

Firth HV, Richards SM, Bevan AP, Clayton S, Corpas M, Rajan D, Van Vooren S, Moreau Y, Pettett RM, Carter NP.2009. DECIPHER: Database of chromosomal imbalance and phenotype in humans using Ensembl resources.Am J Hum Genet 84:524-533.

Gao W, Peng Y, Liang G, Liang A, Ye W, Zhang L, Sharma S, Su P, Huang D. 2013. Association between common variants near LBX1 and adolescent idiopathic scoliosis replicated in the Chinese Han population. PLOS ONE8:e53234. 
Gross MK, Dottori M, Goulding M. 2002. Lbx1 specifies somatosensory association interneurons in the dorsal spinal cord. Neuron 34:535-549.

Gurrieri F, Prinos P, Tackels D, Kilpatrick MW, Allanson J, Genuardi M, Vuckov A, Nanni L, Sangiorgi E, Garofalo G, Nunes ME, Neri G, Schwartz C, Tsipouras P. 1996. A split hand-split foot (SHFM3) gene is located at 10q24$>25$. Am J Med Genet 62:427-436.

Jagla T, Bellard F, Lutz Y, Dretzen G, Bellard M, Jagla K. 1998. ladybird determines cell fate decisions during diversification of Drosophila somatic muscles. Development 125:3699-3708.

Kruger M, Schafer K, Braun T. 2002. The homeobox containing gene Lbx1 is required for correct dorsal-ventral patterning of the neural tube. J Neurochem 82:774-782.

Lyle R, Radhakrishna U, Blouin JL, Gagos S, Everman DB, Gehrig C, Delozier-Blanchet C, Solanki JV, Patel UC,Nath SK, Gurrieri F, Neri G, Schwartz CE, Antonarakis SE. 2006. Split-hand/split-foot malformation 3 (SHFM3) at 10q24, development of rapid diagnostic methods and gene expression from the region. Am J Med Genet A140:1384-1395.

Marosy B, Justice CM, Vu C, Zorn A, Nzegwu N, Wilson AF, Miller NH. 2010. Identification of susceptibility loci for scoliosis in FIS families with triple curves. Am J Med Genet A 152A:846-855.

Martin BL, Harland RM. 2006. A novel role for Ibx1 in Xenopus hypaxial myogenesis. Development133:195208.

Martin Fernandez-Mayoralas D, Fernandez-Jaen A, Garcia-Segura JM, Quinones-Tapia D. 2010. Neuroimagen en el trastorno por deficit de atencion/hiperactividad. Rev Neurol 50:S125-S133.

Massat I, Slama H, Kavec M, Linotte S, Mary A, Baleriaux D, Metens T, Mendlewicz J, Peigneux P. 2012. Working memory-related functional brain patterns in never medicated children with ADHD. PLOS ONE 7:e49392.

Mennerich D, Braun T. 2001. Activation of myogenesis by the homeobox gene Lbx1 requires cell proliferation.EMBO J 20:7174-7183. 
Muller T, Brohmann H, Pierani A, Heppenstall PA, Lewin GR, Jessell TM, Birchmeier C. 2002. The homeodomain factor lbx1 distinguishes two major programs of neuronal differentiation in the dorsal spinal cord. Neuron34:551-562.

Neale BM, Medland SE, Ripke S, Asherson P, Franke B, Lesch KP, Faraone SV, Nguyen TT, Schafer H, Holmans P, Daly M, Steinhausen HC, Freitag C, Reif A, Renner TJ, Romanos M, Romanos J, Walitza S, Warnke A, Meyer J,Palmason H, Buitelaar J, Vasquez AA, Lambregts-Rommelse N, Gill M, Anney RJ, Langely K, O'Donovan M,Williams N, Owen M, Thapar A, Kent L, Sergeant J, Roeyers H, Mick E, Biederman J, Doyle A, Smalley S, Loo S,Hakonarson H, Elia J, Todorov A, Miranda A, Mulas F, Ebstein RP, Rothenberger A, Banaschewski T, Oades RD,Sonuga-Barke E, McGough J, Nisenbaum L, Middleton F, Hu X, Nelson S, Psychiatric GCAS. 2010. Metaanalysis of genome-wide association studies of attention-deficit/hyperactivity disorder. J Am Acad Child Adolesc Psychiatry 49:884-897.

Ochi H, Westerfield M. 2009. Lbx2 regulates formation of myofibrils. BMC Dev Biol 9:13.

Roscioli T, Taylor PJ, Bohlken A, Donald JA, Masel J, Glass IA, Buckley MF. 2004. The 10q24-linked split hand/split foot syndrome (SHFM3): Narrowing of the critical region and confirmation of the clinical phenotype.Am J Med Genet A 124A:136-141.

Schafer K, Neuhaus P, Kruse J, Braun T. 2003. The homeobox gene Lbx1 specifies a subpopulation of cardiac neural crest necessary for normal heart development. Circ Res 92:73-80.

Schmitteckert S, Ziegler C, Kartes L, Rolletschek A. 2011. Transcription factor Ibx1 expression in mouse embryonic stem cell-derived phenotypes. Stem Cells Int 2011:130970.

Sieber MA, Storm R, Martinez-de-la-Torre M, Muller T, Wende H, Reuter K, Vasyutina E, Birchmeier C. 2007.Lbx1 acts as a selector gene in the fate determination of somatosensory and viscerosensory relay neurons in the hindbrain. J Neurosci 27:4902-4909.

Takahashi Y, Kou I, Takahashi A, Johnson TA, Kono K, Kawakami N, Uno K, Ito M, Minami S, Yanagida H,Taneichi H, Tsuji T, Suzuki T, Sudo H, Kotani T, Watanabe K, Chiba K, Hosono N, Kamatani N, Tsunoda T,Toyama Y, Kubo M, Matsumoto M, Ikegawa S. 2011. A genome-wide association study identifies common variants near LBX1 associated with adolescent idiopathic scoliosis. Nat Genet 43:1237-1240.

Vaidya CJ. 2012. Neurodevelopmental abnormalities in ADHD. Curr Top Behav Neurosci 9:49-66. Watanabe S, Kondo S, Hayasaka M, Hanaoka K. 2007. Functional analysis of homeodomain-containing transcription factor Lbx1 in satellite cells of mouse skeletal muscle. J Cell Sci 120:4178-4187. 
Watanabe S, Matsushita S, Hayasaka M, Hanaoka K. 2011. Generation of a conditional null allele of Lbx1.Genesis 49:803-810.

Willcutt EG. 2012. The prevalence of DSM-IV attention-deficit/hyperactivity disorder: A meta-analytic review.Neurotherapeutics 9:490-499.

Wotton KR, Weierud FK, Dietrich S, Lewis KE. 2008. Comparative genomics of Lbx loci reveals conservation of identical Lbx ohnologs in bony vertebrates. BMC Evol Biol 8:171. 